\title{
Ergonomics and musculoskeletal pain among postgraduate students and faculty members of the School of Dentistry of the University of Barcelona (Spain). A cross-sectional study
}

\author{
Karmen Harutunian ${ }^{1}$, Jordi Gargallo-Albiol ${ }^{2}$, Rui Figueiredo ${ }^{3}$, Cosme Gay-Escoda ${ }^{4}$ \\ ${ }^{1}$ DDS. Fellow of Oral Surgery and Implantology, School of Dentistry, University of Barcelona (Spain) \\ ${ }^{2}$ DDS, PhD. Master of Oral Surgery and Orofacial Implantology. Professor of the Master in Oral Surgery and Implantology. \\ School of Dentistry, University of Barcelona. Investigator of the IDIBELL Institute. Barcelona (Spain) \\ ${ }^{3}$ DDS. Master of Oral Surgery and Implantology. Associate professor of Oral Surgery and professor of the Master in Oral Surgery \\ and Implantology. School of Dentistry of the University of Barcelona. Investigator of the IDIBELL Institute. Barcelona (Spain) \\ ${ }^{4}$ DDS, MD, PhD. Chairman and Professor of Oral and Maxillofacial Surgery. Director of the Master in Oral Surgery and Im- \\ plantology. School of Dentistry of the University of Barcelona. Investigating coordinator of the IDIBELL Institute. Oral and \\ Maxillofacial Surgeon of the Teknon Medical Center, Barcelona (Spain)
}

Correspondence:

Centro Médico Teknon

Instituto de investigación IDIBELL

C/Vilana 12

08022 - Barcelona (Spain)

cgay@ub.edu

Received: $12 / 03 / 2010$

Accepted: 14/03/2010

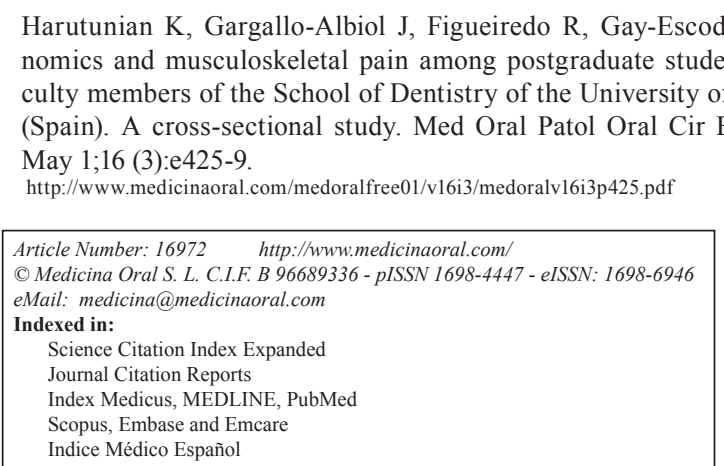

\begin{abstract}
Objectives: To evaluate the intensity and location of musculoskeletal pain suffered by students and professors from different postgraduate programs of the School of Dentistry of the University of Barcelona (Spain), to identify the variables related to the occurrence of musculoskeletal symptoms and signs, and to establish possible preventive measures for such disorders.

Materials and Methods: A cross-sectional study was made among students and faculty members from different postgraduate courses of the School of Dentistry at the University of Barcelona between May and June 2007. A total of 74 dentists (54 postgraduate students and 20 faculty members) completed an anonymous questionnaire containing 19 questions. The variables were divided into three main groups: sociodemographic information, ergonomic features and musculoskeletal pain arising from professional practice.

Results: Most of the dentists (79.8\%) had experienced some kind of musculoskeletal pain in the last 6 months. On comparing the different locations of pain (lumbar, cervical, dorsal, wrist, shoulder and others), the neck was found to be the most commonly affected location (58\% of all subjects), and only $34 \%$ of the respondents took some preventive measures against musculoskeletal disorders. Women showed a higher frequency of intense pain involving the cervical, lumbar, dorsal and wrist areas $(\mathrm{p}<0.05)$. A higher incidence of wrist pain was recorded in professionals exclusively dedicated to oral surgery $(\mathrm{p}<0.05)$. No statistically significant correlation was found between the workload (hours) and pain in the different anatomical locations ( $>0.05$ ).

Conclusions: An important incidence of pain symptoms secondary to musculoskeletal disorders was observed, particularly in the cervical region. Females and younger dentists showed a higher frequency of such symptoms. The implementation of preventive measures is necessary, in view of the high incidence of these disorders.
\end{abstract}

Key words: Musculoskeletal disorders, ergonomics, preventive measures, dentists. 


\section{Introduction}

Musculoskeletal disorders are characterized by the presence of discomfort, disability or persistent pain in the joints, muscles, tendons and other soft parts, caused or aggravated by repeated movements and prolonged awkward or forced body postures. Dentists are usually included among the professionals with a higher incidence of musculoskeletal diseases in the course of their professional life $(1,2)$.

Important advances in the field of ergonomics in dentistry have been made in recent years. These advances have focused on furnishing and the working environment, though preventive measures related to the dental professional have not been adopted. The main risk factors involved must be identified in order to design adequate prevention strategies $(3,4)$.

The objectives of this study were to assess the intensity and location of musculoskeletal pain suffered by students and faculty members from different graduate programs (Oral Surgery, Pedodontics, Periodontics, Prosthodontics, Endodontics and Integrated Adult Dentistry) of the School of Dentistry of the University of Barcelona (Spain); to identify variables associated with the onset of symptoms and signs of musculoskeletal disorders; and to establish possible preventive measures.

\section{Materials and Methods}

A cross-sectional study was conducted between May and June 2007 among 54 students and 20 teaching faculty members from various postgraduate programs (Oral Surgery and Implantology, Pedodontics, Periodontics, Prosthodontics, Endodontics and Integrated Adult Dentistry) of the School of Dentistry of the University of Barcelona (Spain). Participant perceptions of symptoms were established with an anonymous questionnaire containing 19 questions that had been used in an earlier study (2). The study variables were divided into three groups according to the classification described by $\mathrm{Bu}-$ garin (2):

1. Sociodemographic information:

- Age and gender, duration and type of professional practice, and leisure activities.

2. Ergonomic features:

- Dominant limbs, weight and height.

- Working hours in the sitting position. Characteristics of the working chair.

- Characteristics of the instrument holder.

- Others: activity between successive visiting patients, work with or without an assistant.

3. Musculoskeletal disorders resulting from professional practice:

- Locations of pain. Additionally, within each region, a visual analog scale (VAS) was included for the quantification of pain. A set of closed or semi-closed questions was added for assessing the following points:
- Consequences of pain: sick leaves, need for analgesics.

- Preventive or mitigating measures: physiotherapy, swimming, others.

- Intensity of work, workload (days and hours of work per week), number of patients seen per week.

Statistical analysis

A descriptive and bivariate analysis (Pearson chisquared test, Student t-test and Pearson correlation coefficient) was performed with the SPSS version 11.5 statistical package (SPSS, SPSS Inc., Chicago, IL, USA). Statistical significance was accepted for $\mathrm{p}<0.05$.

\section{Results}

The questionnaire was completed by 74 professionals (54 students and 20 teaching faculty members) out of an initial sample of 100 subjects. Regarding the sociodemographic variables, $53 \%$ of the dentists who participated in the study were women, and the average age was 28.9 years (range 23-52 years). The professionals worked an average of 4.6 days and 31.6 hours a week, and attended an average of 45.8 patients during that time.

In relation to the ergonomic features, practitioners sat $77.5 \%$ of their working hours, and $89.2 \%$ were right handed. All of the respondents claimed to have a chair with a back, though $28 \%$ did not use it. In turn, $52.7 \%$ of the dentists were not involved in any activity between successive visiting patients.

With regards to the musculoskeletal disorders, $79.8 \%$ of the participants reported musculoskeletal pain during the past 6 months. The neck region was the most frequently affected area (58\% of the participants), followed by pain in the lumbar area (52.7\%), back pain $(40.5 \%)$, wrist pain $(27.1 \%)$ and pain in the shoulders $(24.3 \%)$ (Table 1). In turn, $17.6 \%$ of the participants suffered pain in a single location, $20.3 \%$ in two locations, and $42 \%$ in three or more locations (mean $=2.16 ; \mathrm{SD}=1.7$ ). Although the incidence of musculoskeletal pain was important, only $15 \%$ of the dentists included in the study applied for sick leave, and $12 \%$ had to use nonsteroidal antiinflammatory drugs (NSAIDs). In turn, 33.8\% of the respondents claimed to perform some preventive activity (sports $52 \%$, correct postures $16 \%$, physiotherapy $16 \%$, stretching $8 \%$, yoga $4 \%$ and sports and massage $4 \%$ ). (Table 2) shows the relationship between the incidence of pain and other variables. Pain in the cervical and lumbar regions was associated with the presence of pain in other locations, with statistically significant values $(p<0.05)$. Wrist pain was more frequent in professionals who also had shoulder pain (Pearson correlation; $\mathrm{p}<0.05$ ). The participants who did stretching or other preventive actions between patients suffered lesser low back pain, though no significant differences were found (Student t-test; $p=0.398$ ). Oral surgeons reported a higher incidence of pain in the wrist than the 
Table 1. Intensity and frequency of pain according to anatomical location.

\begin{tabular}{|c|c|c|c|c|c|c|c|}
\hline Location & Gender & $\begin{array}{l}\text { Mean* } \\
(0-100)\end{array}$ & $\begin{array}{c}\text { Professionals with } \\
\text { pain }\end{array}$ & $\begin{array}{l}\text { Mean* } \\
(0-100)\end{array}$ & $\begin{array}{l}\text { Mild } \\
\text { n (\%) }\end{array}$ & $\begin{array}{l}\text { Moderate } \\
\text { n (\%) }\end{array}$ & $\begin{array}{c}\text { Severe } \\
\text { n (\%) }\end{array}$ \\
\hline \multirow{2}{*}{ Cervical } & Female & 29.3 & \multirow{2}{*}{$\begin{array}{c}43 \\
(58.1 \%)\end{array}$} & \multirow{2}{*}{20.9} & \multirow{2}{*}{$\begin{array}{c}25 \\
(33.8 \%)\end{array}$} & \multirow{2}{*}{$\begin{array}{c}16 \\
(21.6 \%)\end{array}$} & \multirow{2}{*}{$\begin{array}{c}2 \\
(2.7 \%)\end{array}$} \\
\hline & Male & 13.4 & & & & & \\
\hline \multirow{2}{*}{ Dorsal } & Female & 20.1 & \multirow{2}{*}{$\begin{array}{c}30 \\
(40.5 \%)\end{array}$} & \multirow{2}{*}{14.9} & \multirow{2}{*}{$\begin{array}{c}17 \\
(22.9 \%)\end{array}$} & \multirow{2}{*}{$\begin{array}{c}10 \\
(13.5 \%)\end{array}$} & \multirow{2}{*}{$\begin{array}{c}3 \\
(4.1 \%)\end{array}$} \\
\hline & Male & 10.1 & & & & & \\
\hline \multirow{2}{*}{ Lumbar } & Female & 25.2 & \multirow{2}{*}{$\begin{array}{c}39 \\
(52.7 \%)\end{array}$} & \multirow{2}{*}{19.8} & \multirow{2}{*}{$\begin{array}{c}22 \\
(29.7 \%)\end{array}$} & \multirow{2}{*}{$\begin{array}{c}13 \\
(17.6 \%)\end{array}$} & \multirow{2}{*}{$\begin{array}{c}4 \\
(5.4 \%)\end{array}$} \\
\hline & Male & 14.9 & & & & & \\
\hline \multirow{2}{*}{ Wrist } & Female & 13.2 & \multirow{2}{*}{$\begin{array}{c}20 \\
(27.1 \%)\end{array}$} & \multirow{2}{*}{8.8} & \multirow{2}{*}{$\begin{array}{c}15 \\
(20.3 \%)\end{array}$} & \multirow{2}{*}{$\begin{array}{c}3 \\
(4.1 \%)\end{array}$} & \multirow{2}{*}{$\begin{array}{c}2 \\
(2.7 \%\end{array}$} \\
\hline & Male & 4.8 & & & & & \\
\hline \multirow{2}{*}{ Shoulder } & Female & 9.7 & \multirow{2}{*}{$\begin{array}{c}18 \\
(24.3 \%)\end{array}$} & \multirow{2}{*}{9.6} & \multirow{2}{*}{$\begin{array}{c}11 \\
(14.8 \%)\end{array}$} & \multirow{2}{*}{$\begin{array}{c}3 \\
(4.1 \%)\end{array}$} & \multirow{2}{*}{$\begin{array}{c}4 \\
(5.4 \%)\end{array}$} \\
\hline & Male & 9.6 & & & & & \\
\hline
\end{tabular}

* Intensity scored by VAS: mild $<40 \mathrm{~mm}$; moderate $40-70 \mathrm{~mm}$; severe $>70 \mathrm{~mm}$. Significant differences were found between males and females regarding pain in all locations except the shoulders (Student t-test; $\mathrm{p}<0.05$ ).

Table 2. Pain and its association to different variables (Pearson's correlation).

\begin{tabular}{|l|c|c|c|c|c|c|c|c|c|}
\hline Pain & $\begin{array}{c}\text { Work } \\
\text { hours }\end{array}$ & $\begin{array}{c}\text { No. patients } \\
\text { attended }\end{array}$ & Age & $\begin{array}{c}\text { Male } \\
\text { gender }\end{array}$ & $\begin{array}{c}\text { Female } \\
\text { gender }\end{array}$ & $\begin{array}{c}\text { Specialty oral } \\
\text { surgery }\end{array}$ & Sports & $\begin{array}{c}\text { Correct body } \\
\text { posture }\end{array}$ & Stretching \\
\hline Cervical & NS & NS & -- & NS & ++ & NS & NS & NS & NS \\
\hline Dorsal & NS & NS & NS & NS & ++ & NS & NS & NS & NS \\
\hline Lumbar & NS & NS & NS & NS & ++ & NS & NS & NS & - \\
\hline Wrist & NS & NS & NS & NS & ++ & ++ & NS & NS & - \\
\hline Shoulder & NS & NS & NS & NS & NS & NS & NS & NS & NS \\
\hline
\end{tabular}

++ significant direct relationship $(\mathrm{p}<0.05)$; -- significant inverse relationship $(\mathrm{p}<0.05)$; + direct relationship $(\mathrm{p}>0.05)$; - inverse relationship $(\mathrm{p}>0.05)$; NS nonsignificant relationship.

rest of the professionals (Student t-test; $p=0.043$ ). No significant correlations were found between workload (weekly days and hours of work and number of attended patients) and pain in the different anatomical locations (Pearson correlation; $\mathrm{p}>0.05$ ).

\section{Discussion}

Almost all published studies on musculoskeletal problems in dentistry have an observational design. Despite their limitations (difficulty in identifying risk factors and questionable utility for diseases of low incidence and short duration), studies using questionnaires, as in 
our case, are useful for identifying the prevalence of a disorder, determining the clinical features of patients, and for designing possible preventive strategies.

Dentists are normally included within the group of professionals at risk of suffering musculoskeletal disorders, due to prolonged awkward or forced postures at work and failure to adopt preventive measures (3). Our study found that most professionals referred some kind of musculoskeletal pain in the last 6 months, in coincidence with the information found in the literature (3). In agreement with different studies, the region most commonly affected by pain was the neck, followed the lumbar zone (3-5). It is important to underscore that the great majority of the respondents had mild symptoms, and that only a small percentage suffered moderate or severe pain.

Lalumandier et al. (4) reported that all dental specialties show a high occurrence of musculoskeletal disorders, but with variations in frequency and order in different locations. Ratzon et al. (5) found musculoskeletal discomfort to be more frequent in the oral surgeon than in other dental specialists, and attributed this to an increased workload (4-6). In our study, oral surgeons suffered more pain in the wrist ( $\mathrm{p}=0.043$ ), though no statistically significant association was found between the pain and workload (Pearson correlations; $p>0.05$ ). The wrist pain in oral surgeons could be explained by specific activities of this specialty, such as suturing. Coinciding with our study, most authors find that females are more susceptible to this type of pain, though the reason is unclear. In any case, this association is not specific to dentistry. Some authors relate this difference to a lesser muscle tone and a higher incidence of osteoporosis among women (6). The role of age is even more controversial. While there are studies that claim that the frequency of pain remains stable with age (7), others believe that musculoskeletal discomfort is maximum around the sixth decade of life (5). A third group of authors believe that discomfort is greater in young professionals. In our study, we found young professionals to have a higher incidence of neck pain. This could be due to incorrect working positions, since older dentists use more indirect vision and usually avoid neck overload (8).

In this work we found that the professionals, although experiencing musculoskeletal discomfort, did not take measures to prevent or lessen the symptoms. Specifically, $33.8 \%$ of our respondents claimed to take some preventive actions. However, these actions were not the most appropriate solution, since the main preventive measures should be changing posture, taking breaks, and stretching between successive patients - and these measures were little used by our subjects. However, no decrease in pain intensity was recorded among the dentists who practiced preventive measures, with the exception of those who performed stretching. These seemingly disappointing results must be analyzed with caution, since professionals showing a higher incidence of pain are those who most frequently try to implement preventive measures (9-12).

According to some studies, improvement in the ergonomics of the dental equipment has not served to reduce the incidence of musculoskeletal disorders (9). The etiology of musculoskeletal disease is multifactorial, with the involvement of biomechanical, individual and psychosocial factors related to work. Consequently, the preventive strategy must be multifactorial and not only focused on ergonomics (10-12). Any useful study on musculoskeletal disorders among dentists should include an analysis of preventive strategies. These strategies in turn should focus on the following areas: ergonomics, breaks at work, general health and physical exercise (10-12).

The ergonomic factors to be taken into account could be summarized as supports of the upper limbs, the use of instruments with large handles, and working with a mechanically adjustable chair presenting an adjustable backrest. The use of indirect vision and correct patient positioning in the dental chair to avoid awkward or forced neck postures are also important. Proper lighting and the use of systems such as magnifiers and microscopes also help reduce fatigue and increase productivity (11-13).

Repetitive movements and prolonged body postures can be expected to cause muscle damage, as well as ligament and joint injuries (9-12). Daily work planning should allow a break for the alternating muscle groups in order to maintain productive work. In our study, $52.7 \%$ of the professionals did not take breaks between attended patients. The Applied Occupational and Environmental Hygiene guidelines recommend at least 6 minutes of rest every hour for professionals who perform repetitive movements $(5,11,12)$. The three types of breaks which are recommended for dentists would be the following:

- Frequent stops and shaking exercises (relaxing of the arms, shaking and dropping them for periods of $15 \mathrm{sec}-$ onds).

- Breaks between successive patients (dentists should perform movements opposite to those done during work, for 2-3 minutes).

- Breaks to allow recovery (periods of 10-15 minutes every 2-3 hours).

General health is another aspect to be taken into account for the correct prevention of musculoskeletal disorders (13). It is essential to dedicate the necessary time to leisure activities, and to implement other measures for the control of mental stress.

Lastly, the preventive role of physical exercise is also a key element to be taken into account. Dental professionals should learn to avoid the various risk factors - the 
ultimate objective being the definition of personalized rehabilitation exercises, stretching and regular aerobic activity. Aerobic exercise has been shown to prevent or improve general pain, facilitate weight loss, and strengthen the torso. The stretching of the muscle and tendon structures in turn appears to be helpful in relieving back pain (10-12).

It thus may be concluded that musculoskeletal pain is common among dentists, with a higher incidence in young women. The neck region is the most affected area. Among the different professionals surveyed, the oral surgeons showed a higher incidence of pain in the wrist.

Regarding prevention, $66.2 \%$ of the respondents took no measures to avoid such problems, while $33.8 \%$ claimed to practice preventive activities, though these were generally performed incorrectly.

\section{References References with links to Crossref-DOI}

1. Pollack R. Dental office ergonomics: how to reduce stress factors and increase efficiency. J Can Dent Assoc. 1996;62:508-10.

2. Bugarin Gonzalez R. Ergonomía y problemas musculoesqueléticos en los odontoestomatologos de Galicia. [Doctoral Thesis]. Santiago de Compostela: Universidad de Santiago de Compostela; 2004.

3. Szymańska J. Disorders of the musculoskeletal system among dentists from the aspect of ergonomics and prophylaxis. Ann Agric Environ Med. 2002;9:169-73.

4. Lalumandier JA, McPhee SD, Parrott CB, Vendemia M. Musculoskeletal pain: prevalence, prevention, and differences among dental office personnel. Gen Dent. 2001;49:160-6.

5. Ratzon NZ, Yaros T, Mizlik A, Kanner T. Musculoskeletal symptoms among dentists in relation to work posture. Work. 2000;15:153158.

6. Lehto TU, Rönnemaa TE, Aalto TV, Helenius HY. Roentgenological arthrosis of the hand in dentists with reference to manual function. Community Dent Oral Epidemiol. 1990;18:37-41.

7. Lehto TU, Helenius HY, Alaranta HT. Musculoskeletal symptoms of dentists assessed by a multidisciplinary approach. Community Dent Oral Epidemiol. 1991;19:38-44.

8. Rundcrantz BL, Johnsson B, Moritz U. Cervical pain and discomfort among dentists. Epidemiological, clinical and therapeutic aspects. Part 1. A survey of pain and discomfort. Swed Dent J. 1990;14:71-80.

9. Rucker LM, Sunell S. Ergonomic risk factors associated with clinical dentistry. J Calif Dent Assoc. 2002;30:139-48.

10. Andrews N, Vigoren G. Ergonomics: muscle fatigue, posture, magnification, and

illumination. Compend Contin Educ Dent. 2002;23:261-6, 268,270,274.

11. Valachi B, Valachi K. Mechanisms leading to musculoskeletal disorders in dentistry. J Am Dent Assoc. 2003;134:1344-50.

12. Valachi B, Valachi K. Preventing musculoskeletal disorders in clinical dentistry: strategies to address the mechanisms leading to musculoskeletal disorders. J Am Dent Assoc. 2003;134:1604-12.

13. Verhagen AP, Bierma-Zeinstra SM, Feleus A, Karels C, Dahaghin $\mathrm{S}$, Burdorf L, et al. Ergonomic and physiotherapeutic interventions for treating upper extremity work related disorders in adults. Cochrane Database Syst Rev. 2004;1:CD003471. 